\title{
AN ASSESSMENT OF AMPICILLIN IN THE TREATMENT OF URINARY TRACT INFECTION
}

\author{
W. Brumfitt, D. A. Leigh, A. Percival and \\ J. D. Williams. \\ Edgware General Hospital, Edgware, Middlesex.
}

THE outcome of a particular infection in the individual patient will depend upon the balance between the pathogenicity of the infecting organism and the natural defence mechanisms of the host. However, these defence mechanisms may be impaired by the presence of a structural or functional abnormality in the host which may then favour persistence and possibly progression of the infection. On the other hand a chemotherapeutic substance may also modify the host-parasite relationship and the effectiveness of such a substance is determined primarily by the sensitivity of the infecting organism to the concentration of the chemotherapeutic agent which can be obtained at the site of bacterial invasion in the tissues or body fluids. The mode of action of the chemotherapeutic substance in terms of bactericidal or bacteriostatic effect and whether it acts upon bacteria in both the resting and the dividing phases is probably also of great importance. As a model for investigating the factors concerned in response to chemotherapy, infection of the urinary tract is in some ways the easiest of infections in the human body to study. Although urine, being a waste product, varies in composition it usually supports the growth of those bacterial pathogens liable to invade the urinary tract and which therefore readily multiply in bladder urine. This and the ease with which satisfactory urine specimens can be obtained, allows accurate quantitative bacteriological analysis to be carried out in order to establish precise criteria for the presence or absence of infection. Furthermore, the urinary tract is accessible to both endoscopic and radiological studies which can demonstrate the presence of even relatively minor underlying abnormalities.

In view of this situation it is surprising that relatively little advance has been made in the last ten years in our knowledge of the fundamental processes governing the response of urinary tract infections to treatment. Following the discovery of the sulphonamides, early reports indicated that these compounds were successful in approximately $80 \%$ of patients with urinary tract infections, (Huber 1936, Kenny, Johnson and von Haebler, 1937). Although many antibiotics have since been used, the results of treatment with these compounds have been little better. It was soon recognised that the most important factor determining the outcome of treatment was the presence of an underlying structural or functional abnormality in the patient. A review by Kass (1955) showed that the failure rate in primary uncomplicated urinary tract infections was $10-20 \%$ almost regardless of the chemotherapeutic agent used, but when infection was associated with an underlying abnormality, approaching $90 \%$ of cases failed. Therefore, the main problem in the treatment of urinary tract infection is to devise more effective methods for treating the $10-20 \%$ who fail the initial conventional course of treatment as well as those who have an underlying abnormality. It is important to realise that although the former group will contain a substantial number who may subsequently be shown to have organic lesions, in many no underlying 


\section{TABLE I}

The Results of Treating 188 Patients with Sulphonamide and Subsequent Investigation of those Failing to Respond to Treatment

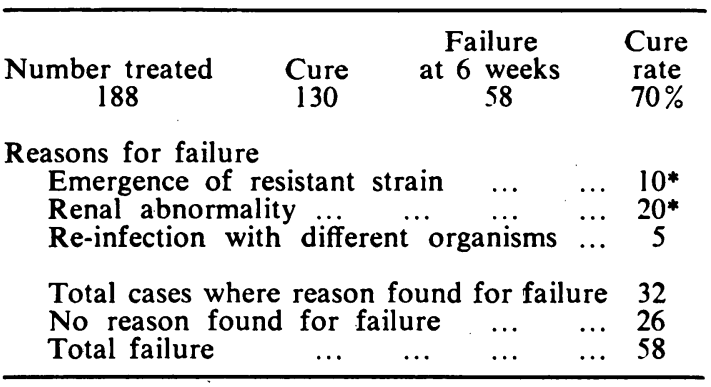

* In three cases with renal abnormality the infecting organism developed resistance to sulphonamide during treatment.

abnormality can be demonstrated. Table I shows the results of treating 188 patients with bacteriuria of pregnancy or symptomatic infection in general practice with sulphonamide. It can be seen that subsequent investigation of the 58 patients in whom treatment failed, revealed abnormalities in 20 but no abnormalities in the remainder.

\section{Importance of Effective Tissue Levels}

A number of antibiotics are largely excreted in an active form by the kidneys with the result that high urinary levels are obtained. Since the normal urinary tract has a tendency to spontaneous eradication of bacteria owing to the dilution and wash out effects of urinary flow, the presence of an antibacterial substance greatly facilitates this process. Failure of treatment when using such an antibiotic can be explained either by an obstruction to the flow of urine or to persistence of a bacterial focus of infection in a tissue site inaccessible to an effective concentration of the antibiotic. It is well established that eradication of bacteria is difficult in the presence of urinary tract obstruction but the part played by tissue involvement in determining the response to the chemotherapy has not yet been clearly defined.

There is no doubt that many patients with urinary tract infections have been successfully treated with urinary disinfectants such as mandelic acid (Rosenheim, 1935) which does not give blood levels but it must be remem- bered that spontaneous cure of even renat tissue infections is probably not uncommo for by no means all patients suffering from clinically typical acute pyelonephritis in the pre-chemotherapeutic era subsequently ha尹 persistent infection. However the importance of blood levels is emphasized by the observation that during treatment with nitrofurantoin clinically obvious pyelonephritis may develo despite the disappearance of bacteria from the urine. (Brumfitt, Percival and Carter 1962\%. This has also been the experience of others (Richards, Riss, Kass and Finland, 1955).

Turck, Browder, Lindemeyer, Brow Anderson and Petersdorf (1962) treateg groups of patients who had chronic urinar tract infections with kanamycin-3-phenj salicylate, chloramphenicol and demethyto chlortetracycline. It was found that there was persistence of infection by the same organism in a high proportion of patients treated witu kanamycin-3-phenyl salicylate which gave onli negligible serum levels whereas the initiat infecting organism was eradicated in a muce greater proportion of patients treated wit chloramphenicol or demethylchlortetracycline which do give appreciable serum levels. These findings suggest that persistence of infecton in a tissue site may be an important reaso for failure of treatment.

One of the main difficulties in assessing response of renal tissue infection to chemo? therapy is the lack of a simple method which enables such a lesion to be recognised in the individual patient with significant bacteriuria This is necessary since a proportion of patients with either no symptoms, or with symptoms referable only to the lower urinar tract, may have clinically inapparent infection of the renal parenchyma. We have found (Brumfitt and Percival, 1964) that patients. with renal tissue infection regularly show high. levels of serum antibody to the infecting organism whereas when infection is confined to the bladder the antibody response usually is either absent or does not exceed the normat range. Furthermore when women with bac teriuria of pregnancy were treated with an eight-day course of sulphonamide, we found that failure of treatment was twice as coms mon in those with raised levels of serurbo antibody than in those with levels within the normal range, suggesting that treatment of patients with renal tissue infection is more difficult (Brumfitt, Williams, Leigh an\& Percival 1964). 


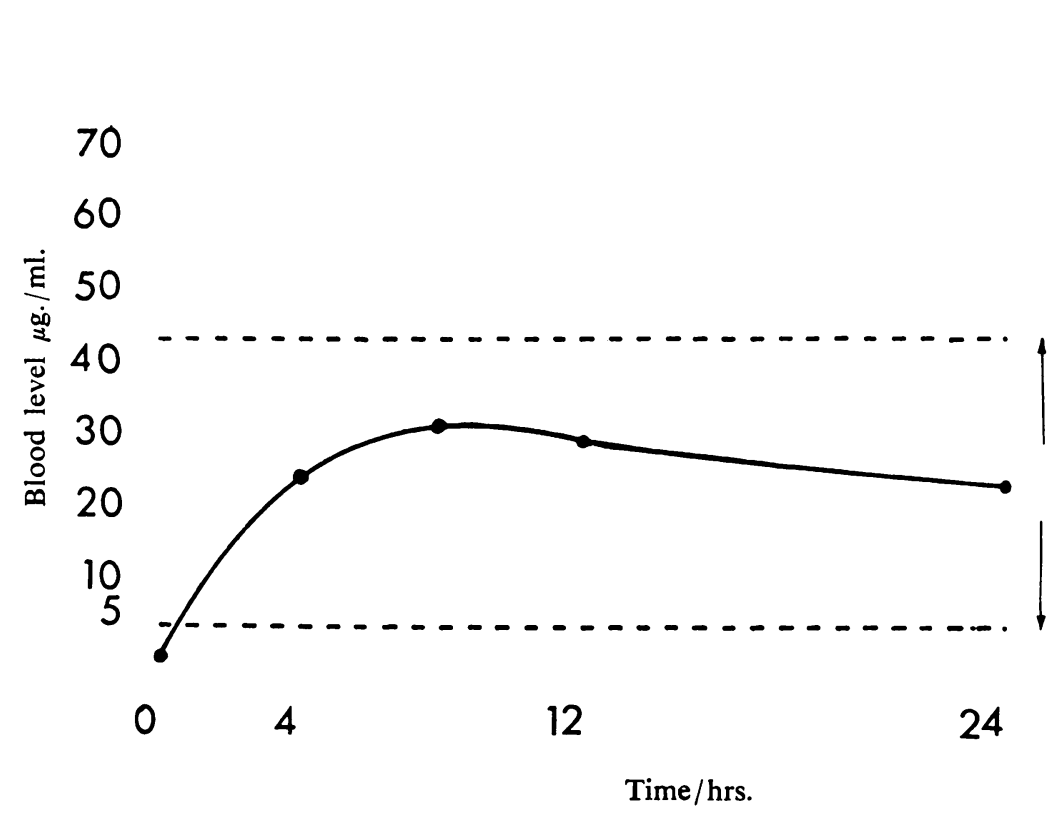

Range of M.I.Cs. for Esch. coli.

FIG. 1.-Relationship of sulphamethoxydiazine blood levels to the M.I.Cs. for Esch. coli following a single oral dose of $1.0 \mathrm{gram}$.

3

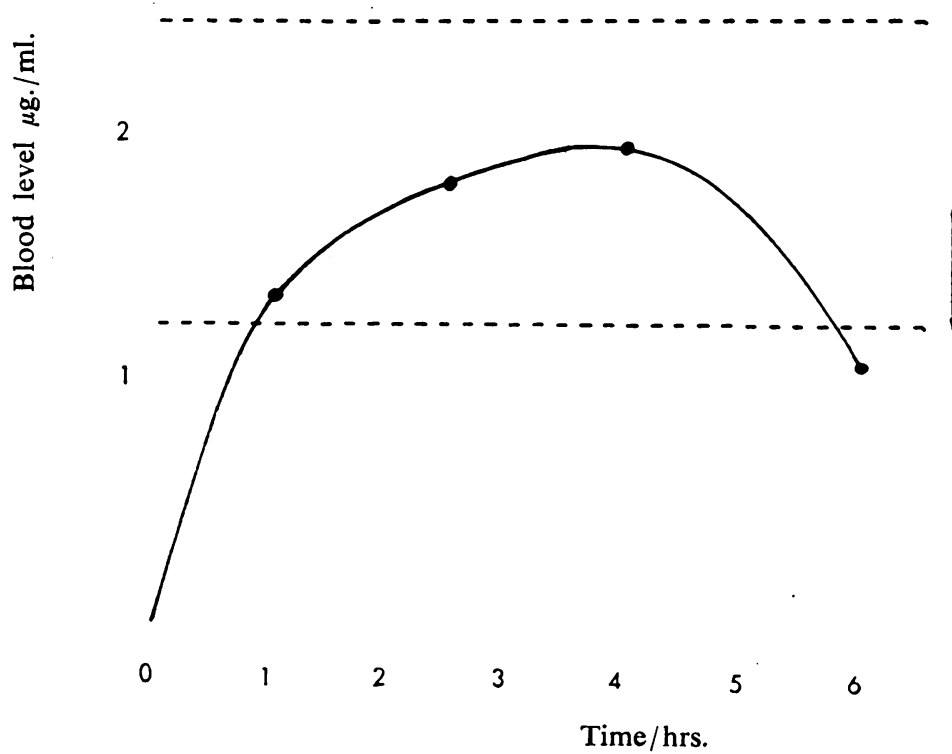

Range of M.I.Cs. for Esch. coli.

Fig. 2.-Relationship of tetracycline blood levels to the M.I.Cs. for Esch. coli following a single oral dose of $500 \mathrm{mg}$.

Relation of Minimum Inhibitory Concentration of Antibiotics to Attainable Blood Levels

For successful treatment of a renal tissue infection, the concentration in the tissue of the chemotherapeutic agent used should exceed the minimum inhibitory concentration (M.I.C.) for the infecting organism. Since very little is known about tissue levels obtained during treatment with antibiotics, it is often assumed that the serum levels are similar if not identi- 


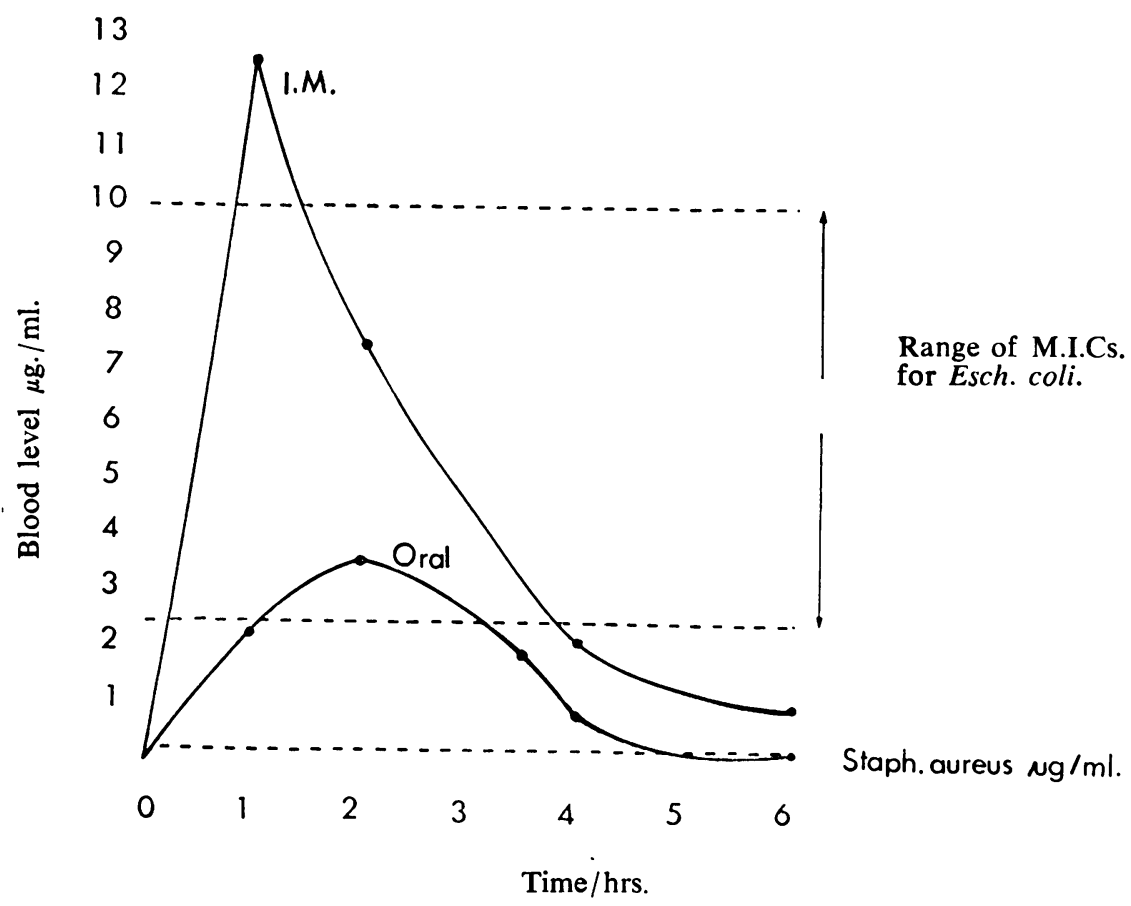

FIG. 3.-Relationship of ampicillin blood levels to the M.I.Cs. for Esch. coli following a single dose (oral and intramuscular) of $500 \mathrm{mg}$.

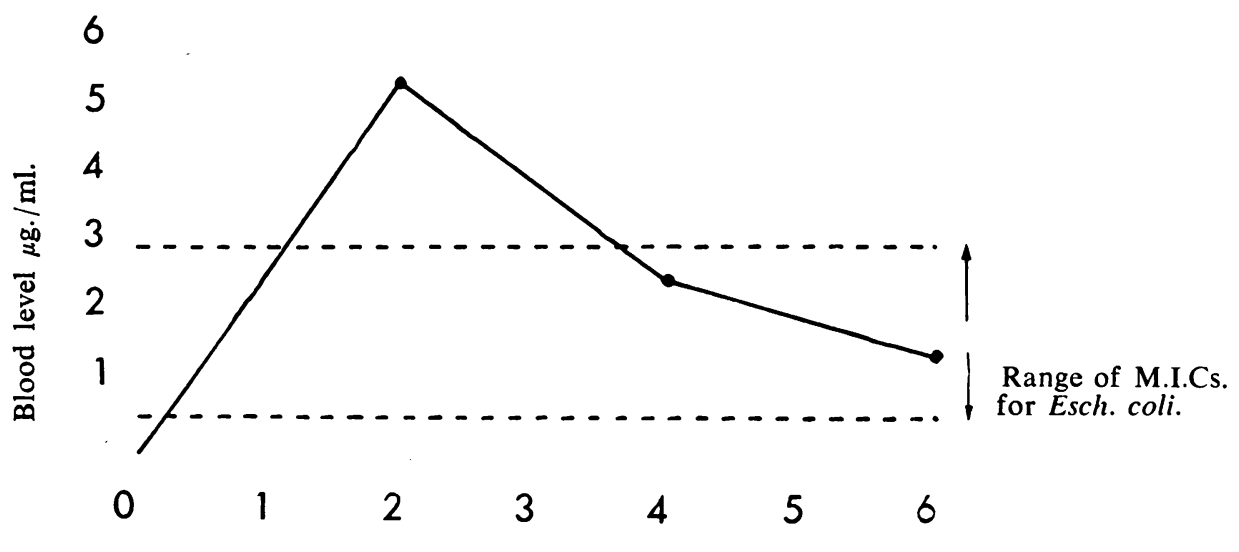

Time/hrs.

FIG. 4.-Relationship of colistin methane sulphonate (polymyxin E) blood levels to the M.I.Cs. for Esch. coli following a single intramuscular injection of $1 \frac{1}{2}$ million units.

cal to the tissue levels. This assumption may not always be valid especially in the renal medullary tissues where diffusion from the tubules could theoretically lead to tissue levels higher than those in the serum, since the concentration of antibiotic in the renal tubules may be several hundred times greater than that irts the serum. On the other hand, a substantialo proportion of some antibiotics is bound too serum protein and may not be available for diffusion into tissues. Therefore, the serum? level may give a false indication of the con- $\square$ 
centration of antibiotic available for tissue penetration. However, at the present time, since tissue levels can be measured only with difficulty in experimental animals, and usually not at all in the patient, serum levels are the best indication which we have of tissue levels of antibiotic.

The minimum inhibitory concentration of some antibiotics for various strains of Esch. coli in relation to the blood levels attainable on conventional therapeutic dosage are shown in Figs. 1-4. Fig. 1 shows that with sulphamethoxydiazine most Esch. coli strains isolated from women with bacteriuria of pregnancy and patients with symptomatic infections in general practice were inhibited by $40 \mu \mathrm{g}$. per ml. and blood levels capable of inhibiting growth of the infecting organisms were commonly obtained following standard dosage. Similar results are obtained for tetracycline (Fig. 2) but following a conventional oral dose of ampicillin (500 mg.) a far greater proportion of Esch. coli strains isolated from patients with urinary tract infections fall outside the therapeutic range as judged by comparison of the M.I.C. and serum level (Fig. 3). It can be seen that much better levels can be obtained by the parental administration of a similar dose of ampicillin (Fig. 3) or colistin methane sulphonate (Fig. 4). The serum level following parenteral injection is also more predictable as the variation in absorption which occurs following oral dosage is avoided.

These findings which are relevant to the general problem of treatment of systemic infections due to Gram negative bacteria, suggest a reason for the difficulty in treating renal tissue infections since with all the chemotherapeutic agents so far available the peak serum levels barely exceed the M.I.C. for many of the infecting organisms and often levels above the M.I.C. are not obtained at all. The results expressed in Figs. 1-4 apply to organisms found to be sensitive by conventional paper disc testing and therefore it should be remembered that a proportion of organisms have been excluded by this procedure. In contrast, treatment of systemic infections due to Gram positive organisms presents no such difficulties because the M.I.C. of the effective antibiotics for sensitive Gram positive organisms are so much lower than with Gram negative bacteria (Fig. 3).

\section{Ampicillin}

Ampicillin is active against many strains of Esch. coli, Proteus mirabilis and Strept. faccalis
(Rolinson and Stevens, 1961) and like other penicillins, it has low toxicity and is bactericidal. The development of resistant variants during treatment is very uncommon (Brumfitt and others 1962, Trafford, McLaren, Lillicrapp and Barnes, Houston and Knox, 1962) and activity in the urine is little affected by $\mathrm{pH}$ variation (Brumfitt and Percival 1962). In our view these properties suggested that ampicillin was a suitable agent for the treatment of urinary tract infections due to sensitive organisms and in particular for those in whom there is infection of the renal tissue. We therefore, decided to assess the value of ampicillin in treatment and have now used it in three different groups of patients.

TABLE II

The Results of Treatment of Urinary Tract Infections using Ampicillin as the Initial Therapy

\begin{tabular}{lcccc}
\hline $\begin{array}{l}\text { Organism } \\
\text { Esch. coli }\end{array}$ & Total & Cure & $\begin{array}{c}\text { Failure } \\
\text { at 6 weeks }\end{array}$ & $\begin{array}{c}\text { Cure } \\
\text { rate }\end{array}$ \\
$\begin{array}{l}\text { Proteus mirabilis } \\
\text { Paracolon spp. }\end{array}$ & 11 & 25 & 5 & $83 \%$ \\
$\begin{array}{l}\text { Total for all } \\
\text { organisms }\end{array}$ & 44 & 36 & 3 & $73 \%$ \\
\hline
\end{tabular}

Ampicillin in Initial Treatment of Urinary Tract Infection

The results of treating 44 patients from hospital and domiciliary practice with $500 \mathrm{mg}$. ampicillin eight hourly for five days are shown in Table II. All organisms were sensitive to $10 \mu \mathrm{g}$. ampicillin per $\mathrm{ml}$. or less. The overall cure rate, as judged by clinical and bacteriological cure when examined six weeks after the end of treatment, was $82 \%$ and similar results have been obtained by others (Trafford et al. 1962, Anderson, Kennedy, Plorde, Shulman and Petersdorf 1964). No attempt was made to follow the eventual clinical progress of the patients who failed or to establish reasons for failure.

\section{Ampicillin in the Treatment of Urinary Infections which have Failed to Respond to Sulphonamide}

Because of the cheapness, low toxicity and satisfactory serum and urinary levels obtained with sulphonamides and because a high proportion of the infecting organisms in patients from general practice or in women with bacteriuria of pregnancy are sensitive we use the short acting sulphonamide sulphadimidine or the long acting compound sulphamethoxydiazine initially in these patients (Brumfitt et al. 
TABLE III

Results of Treatment using either Ampicillin or Tetracycline in Cases of Urinary Tract Infection which Failed to Respond to Sulphonamide

\begin{tabular}{|c|c|c|c|c|c|c|}
\hline \multirow[b]{2}{*}{ Organism } & \multicolumn{3}{|c|}{ AMPICILLIN } & \multicolumn{3}{|c|}{ TETRACYCLINE } \\
\hline & No. & $\begin{array}{l}\text { Failures } \\
\text { at } 6 / 52\end{array}$ & $\begin{array}{l}\text { Cure } \\
\text { rate }\end{array}$ & No. & $\begin{array}{l}\text { Failures } \\
\text { at } 6 / 52\end{array}$ & $\begin{array}{l}\text { Cure } \\
\text { rate }\end{array}$ \\
\hline $\begin{array}{l}\text { Esch. coli } \\
\text { Proteus mirabilis }\end{array}$ & $\begin{array}{r}26 \\
2\end{array}$ & $\begin{array}{c}11 \\
1\end{array}$ & $\begin{array}{c}58 \% \\
0\end{array}$ & 11 & 7 & $36 \%$ \\
\hline Paracolon spp. & $\overline{2}$ & 0 & - & 1 & $\mathbf{0}$ & - \\
\hline Aerobacter aerogenes & - & - & - & 2 & 0 & - \\
\hline $\begin{array}{l}\text { Total for all organisms } \\
\text { Renal abnormalities } \\
\text { on follow up }\end{array}$ & 30 & 12 (58\%) & $60 \%$ & 14 & 7 & $50 \%$ \\
\hline
\end{tabular}

1964). However, if these patients fail to respond a second course of sulphonamide is usually unsuccessful even though the organism remains sensitive. In a series of 10 patients with sensitive organisms who failed to respond to sulphonamide only two $(20 \%)$ were cleared of infection by a second course of sulphonamide and we have discontinued this regime of treatment.

If sulphonamide failures were treated with ampicillin $(500 \mathrm{mg}$. eight hourly for seven days) the cure rate was $60 \%$ which though lower than the $82 \%$ when ampicillin was used initially was nevertheless substantial. If blood and urine levels of oral ampicillin and sulphonamide are compared and these results related to the M.I.C. of the organisms treated (Figs. 1 and 3) the reason for success of ampicillin and failure of sulphonamide is not immediately clear since blood levels in relation to M.I.C. are more satisfactory with sulphonamide. The possibility that the better results with ampicillin may have been a reflection of the greater effectiveness of a bactericidal rather than a bacteriostatic antibiotic is not supported by the finding that treatment of sulphonamide failures with tetracycline gave results apparently almost as good as ampicillin (Table III). However, investigation of the patients in whom infection by the same organism persisted despite treatment with sulphonamide and then either ampicillin or tetracycline showed the presence of underlying abnormalities in seven out of 12 failures in the ampicillin group and two out of seven in the tetracycline group (Table III). The abnormalities found included renal calculi and congenital lesions such as calyceal cyst and double ureter and pelvis.

\section{Parenteral Ampicillin}

Where it was felt necessary to obtain blood levels in excess of the M.I.C. of the infecting organisms, we have treated a number of hospi- tal patients with ampicillin given by intramusw cular injection $(500 \mathrm{mg}$. six hourly for five days).

Patients were divided into three group according to the presenting features and the groups and results of treatment are shown iff Table IV. In eight patients with clinical feature? of acute pyelonephritis a rapid response was obtained and all patients showed clinical an\&ु bacteriological cure at follow-up examination six weeks after the end of treatment. On the other hand, only seven of the 14 patients witlo persistent infection by the same organisne associated with an underlying renal abnorne등 lity were successfully treated and five of these successes had become infected by a differente organism during the six week follow-up peried The results were somewhat better where perio sistent infection was not associated with a? demonstrable abnormality, six of nine patients being cured but in two of these infection by an different organism had occurred when examined six weeks after the end of treatment

\section{Conclusions}

Initial Treatment of Urinary Tract Infection

If the high incidence of chronic renal disease resulting from urinary tract infection is to be reduced effective treatment of the primary? attack is required and because of the unrelia bility of symptoms as a guide to the presence of infection (Mond, Percival, Williams and Brumfitt 1964) a specimen of urine should be taken before starting empirical treatment and? therapy immediately adjusted where the organ $\frac{D}{O}$ ism is found to be resistant. Patients known to be susceptible to urinary tract infection, $\stackrel{N}{\circ}$ e.g. pregnant women, diabetics, should have the urine screened for bacteriuria. Since most patients remain ambulant and a number are $e^{\omega}$ at work some form of oral therapy is desirable in the first instance.

As the majority of strains of Esch. coli and Proteus mirabilis which cause spontaneous 
TABLE IV

The Results of Using Intramuscular Ampicillin in 3 Groups of Patients

\begin{tabular}{|c|c|c|c|c|c|c|}
\hline & & Number & Immedia & te Result & Foll & \\
\hline & & studied & Success & Failure & Success & Failure \\
\hline Group I & Acute pyelonephritis & 8 & 8 & 0 & 8 & 0 \\
\hline Group II & Persistent infection with & 14 & 9 & 5 & 7* & 7 \\
\hline Group III & $\begin{array}{l}\text { Persistent infection no } \\
\text { renal abnormality }\end{array}$ & 9 & 7 & 2 & 6 & 3 \\
\hline
\end{tabular}

*Two patients in group 3 and five in group 2 have become re-infected with a different organism

infection in domiciliary practice are sensitive to sulphonamide (Mond et al., 1964) we usually recommend this therapy in the first instance and the patient is seen three days later when the results of culture and sensitivity tests are available. If the organism is sensitive to sulphonamide this treatment is continued for a further 5-10 days and the urine re-examined four days after the end of treatment and again six weeks later if clear of infection. Patients with a history of sulphonamide sensitivity are given ampicillin 500 mg. t.d.s., for seven days as primary treatment.

\section{The Treatment of Sulphonamide Failures}

Sulphonamides are successful in eradication of primary infections due to sensitive organisms in about $75 \%$ of patients. Of those who fail, most are due to the persistence of sulphonamide sensitive strains within the renal tract although development of resistant mutants during treatment occurs in some cases. For treatment of these failures we use oral ampicillin which is bactericidal, there is little tendency to development of resistance and it is little affected by $\mathrm{pH}$ variation of the urine. With regard to the blood level found after oral administration, there is evidence that this frequently does not exceed the M.I.C. of infecting Esch. coli strains (Brumfitt et al., 1962; Neumann, 1962). However, the extent of diffusion of antibiotics in the renal tissues is at present unknown but the satisfactory clinical results with ampicillin using dosages which give blood levels which barely reach the M.I.C. of the infecting organism suggests that concentration of the antibiotic may occur in the renal tissues as well as in the urine (Brumfitt, Percival and Williams 1964).

In summary we use oral ampicillin for treating urinary tract infections due to sensitive organisms in the following circumstances:

1. As initial treatment for patients who have a history of hypersensitivity to sulphonamide or when the infecting organism is resistant to sulphonamide.

2. In patients who have typical clinical features of pyelonephritis (indicating extensive renal involvement).

3. Where treatment with sulphonamide has failed.

It must be emphasized that the duration of therapy should not depend upon the relief of symptoms and a minimum of seven days therapy should be given no matter how quickly symptoms subside. Over half the patients in our series who failed to respond to sulphonamide and ampicillin were found to have organic abnormalities which in many cases were amenable to surgical treatment. Therefore failure to respond to both sulphonamide and ampicillin is a clear indication for further investigation by the radiologist and genitourinary surgeon.

\section{Parenteral Ampicillin}

The persistence of infection without organic abnormality means that the renal lesion is more inaccessible and parenteral therapy aimed at producing higher blood levels is indicated. The substances available for this purpose are colistin methane sulphonate, streptomycin and kanamycin and parenteral ampicillin. Which of these antibiotics is most effective in treating severe and persistent renal infections remains to be elucidated.

Injections of $500 \mathrm{mg}$. ampicillin are required at intervals of six hours or less to maintain adequate blood levels and therefore treatment is best given in hospital. We consider the indications for parenteral therapy to be as follows:-

(a) For patients who have been given an adequate trial of oral therapy, but infection by the same organism persists in the absence of a demonstrable renal lesion. 
(b) For patients with pronounced clinical features of acute pyelonephritis where rapid control to limit renal damage is desirable.

(c) For patients known to have extensive renal damage where there is a danger of infection precipitating renal failure as well as extending the renal lesion.

(d) Post-operative patients where oral therapy is impracticable or where absorption is in doubt.

Finally, we do not wish to claim that ampicillin is superior to all other drugs in the treatment of urinary tract infection. More comparative trials are needed before the superiority of one antibiotic over another can be established.

\section{REFERENCES}

Anderson, K. N., Kennedy, R. P., Plorde, J. J., Shulman, J. A., and Petersdorf, R. G. (1964): J. Amer. med. Ass., 187, 555.

BrumfitT, W., and Percival, A. (1962): Lancet, i,
Brumfitt, W., Percival, A., and Carter, M. R (1962): Lancet, i, 130.

BRUmfits, W., and Percival, A. (1964): 2nd Intere national Pyelonephritis Symposium. To be published.

Brumfitt, W., Williams, J. D., Leigh, D. A., and Percival, A. (1964): 2nd International Pyelone? phritis Symposium. To be published.

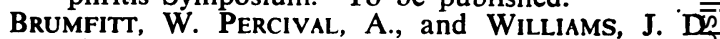
(1964): Brit. J. clin. Pract., 18, 503.

HuBER, H. G. (1936): Munchen. med. Woçhenschr 83, 2014.

KASS, E. H. (1955): Amer. J. Med., 18, 764.

KenNy, M., Johnson, F. D., and von Haebler, (1937): Lancet, ii, 119.

Mond, N. C., Percival, A., Williams, J. D., ang BRUMFITT, W. (1964): In the press.

Richakd, W. A., RisS, E., KASS, E. H., and FinLAND M. (1955): Arch. intern. Med., 96, 437.

Rolinson, G. N., and STEvens, S. (1961): Brit med. J., ii, 191.

Rosenheim, M. L. (1935): Lancet, i, 1032.

Trafford, J. A. P., Mclaren, D. M., Lillicrap? D. A., Barnes, R. D. S., Houston, J. C., angi KNoX, R. (1962): Lancet, i, 987.

TURCK, M., BROWDER, A. A., LINDERMEYER, R. I? Brown, N. K., ANDERSON, K. N., and PeTERSDORF, R. G. (1962): New Engl. J. med., 267, 999

\title{
TREATMENT OF URINARY TRACT INFECTIONS WITH AMPICILLIN
}

\author{
Peter Naumann \\ From the Institute of Clinical Bacteriology and \\ Serology of the University of Hamburg.
}

(Director: Professor G. B. Roemer).

THE therapeutic evaluation of a new antibiotic should not be carried out solely according to clinical criteria. The course of a bacterial infection depends on too many individual factors and imponderables. The therapeutic value of an antibiotic cannot, therefore always be assessed objectively by comparing clinically cured or improved cases with those who failed to respond. After all, a not inconsiderable number of infections is cured without any or with only inadequate therapy and may then be quoted as evidence in favour of a preparation which actually is ineffective. On the other hand, failure to respond may be wrongly ascribed to an "ineffective" antibiotic, even though the bacterial process has been controlled, or is capable of being controlled, provided the drug is given in adequately high doses. "Clinical cure" is a complex event which depends on the defen- sive potential of the body as a whole, and is not always easy to make a true assess ment of the part played by the antibiolic-both in the cured case and in that which fails to respond. This applies particularly to infections of the urinary tract, for even aftee successful eradication of one organism re infection by an unrelated bacterial strairf frequently results in apparent failure of therapys For this reason assessment of a drug such as ampicillin should not be based on the number of "clinical cures", but primarily on the cons" sideration whether the bacteriological effecf has been attained which should. be expected from this antibiotic.

\section{Present Series}

Using the bacteriological examination of the urine to diagnose the presence of infec tion, an attempt has been made during $1960^{\circ}$ 